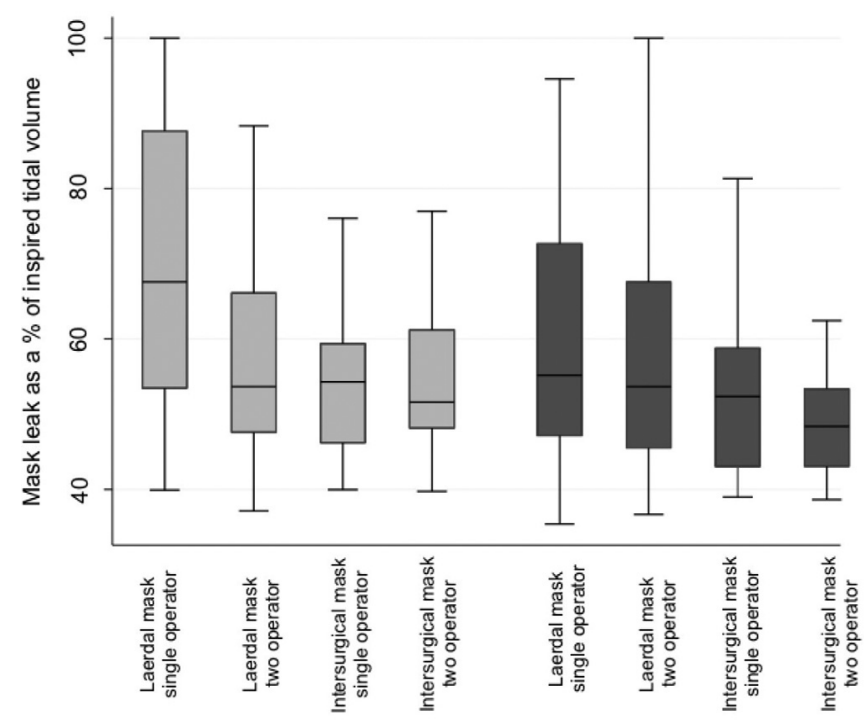

Abstract PS-224 Figure 1

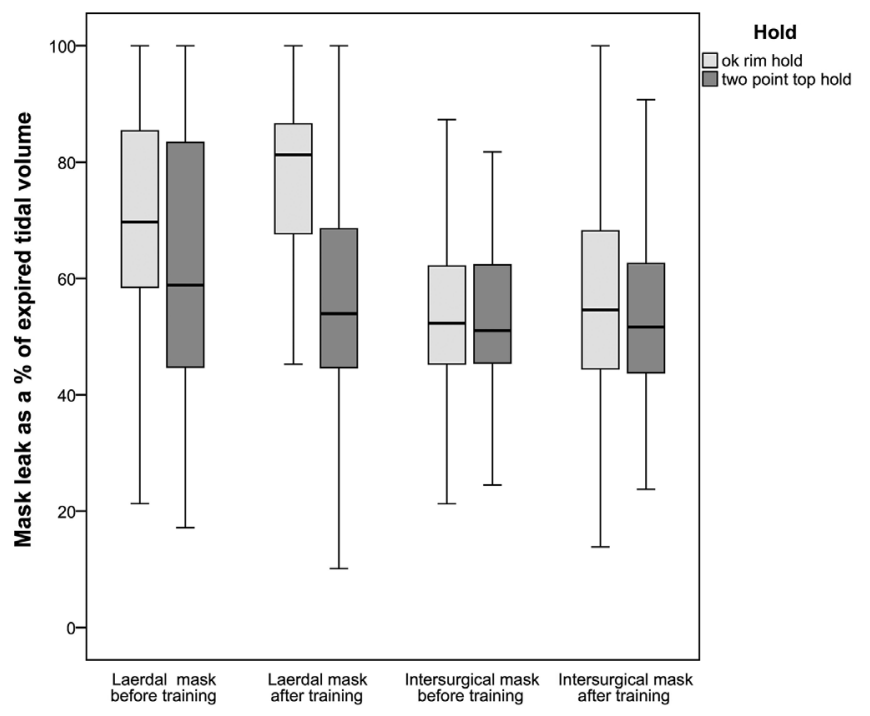

Abstract PS-224 Figure 2

0.4 ) and chin lift manoeuvre (score: $2.3 \pm 0.2$ vs. $3.5 \pm 0.2$ ) during PPV, however mask leak was not significantly reduced. Conclusion A self-instructional educational video on adequate bag mask ventilation significantly improves performance quality scores in novice health care providers.

\section{PS-225 RISK FACTORS (RF) ASSOCIATED WITH ADVANCED NEONATAL RESUSCITATION IN $=34$ W GA NEWBORNS: A MULTICENTER, PROSPECTIVE, CASE-CONTROLLED STUDY. THE ADVANCED NEONATAL RESUSCITATION (ANR) STUDY}

${ }^{1} \mathrm{JP}$ Berazategui, ${ }^{2} \mathrm{~A}$ Aguilar, ${ }^{3} \mathrm{M}$ Escobedo, ${ }^{4} \mathrm{~F}$ Althabe, ${ }^{5} \mathrm{R}$ Ginsburg, ${ }^{5} \mathrm{~F}$ De Almeida, ${ }^{6} \mathrm{G}$ Albornoz, ${ }^{7} \mathrm{~F}$ Saker, ${ }^{8} \mathrm{MG}$ Puig, ${ }^{9} \mathrm{D}$ Amado, ${ }^{10} \mathrm{M}$ Valera, ${ }^{4} \mathrm{E}$ Szyld. ${ }^{1}$ Maternal and Infant, FUNDASAMIN / Hospital Universitario Austral, Pilar - Derqui, Argentina; ${ }^{2}$ Maternal and Infant, FUNDASAMIN (Fundacion Para La Salud Materno Infantil), Buenos Aires, Argentina; ${ }^{3}$ Maternal and Infant, University of Oklahoma, Oklahoma, USA; ${ }^{4}$ Maternal and Infant, IECS Instituto de Efectividad Clínica y Sanitaria, Buenos Aires, Argentina; ${ }^{5}$ Maternal and Infant, Escola P. de Medicina da Universidade F. de Sao Paulo, Sao Paulo, Brazil; ${ }^{6}$ Maternal and Infant, Clinica y Maternidad Suizo Argentina, Buenos Aires,

\begin{tabular}{llll} 
Abstract PS-225 Table 1 & & & \\
\hline Variables & OR & P & $95 \%(C I)$ \\
GA $<37 w k(G A<37)$ & 3.0 & 0.001 & $(2.0-4.6)$ \\
Eclampsia (EC) & 6.0 & 0.049 & $(1.0-36.6)$ \\
Maternal fever during labour (MFL) & 7.8 & 0.001 & $(3.1-20.0)$ \\
Clinical chorioamnionitis (CC) & 6.1 & 0.005 & $(1.7-22.0)$ \\
Fetal bradycardia (FB) & 20.9 & 0.001 & $(11.3-38.6)$ \\
Abruptio placentae (AP) & 21.7 & 0.001 & $(8.1-57.7)$ \\
MSAF & 11.3 & 0.001 & $(7.3-17.6)$ \\
Emergency CS (ECS) & 14.1 & 0.001 & $(8.6-23.1)$ \\
General anaesthesia (Ga) & 17.2 & 0.001 & $(6.9-42.9)$ \\
PROM $>18$ h & 2.10 & 0.003 & $(1.2-3.4)$ \\
\hline
\end{tabular}

Argentina; ${ }^{7}$ Maternal and Infant, Cleveland Clinic, Cleveland, USA; ${ }^{8}$ Maternal and Infant, Maternidad Martin, Rosario, Argentina; ${ }^{9}$ Maternal and Infant, Maternidad NS de la Merced, Tucuman, Argentina; ${ }^{10}$ Maternal and Infant, Hospital Feernandez, Buenos Aires, Argentina

\subsection{6/archdischild-2014-307384.524}

Background Approximately $1 \%$ of newborns (NB) require advanced resuscitation (AR) [intubation (ET), and/or chest compression (CC) and/or medication (ME)] at birth. The NRP recommends checking risk factors maternal (MF), intrapartum (IF) and fetal (FF) before each birth (evidence level of expert recommendation) but the need for a team with advanced skills after risk factors have been identified remains undetermined. This imprecision leads to underprovision of expertise which is unsafe or costly overprovision of expertise.

Objective To evaluate the relationship of RF and the need for AR in NB $\geq 34$ w gestational age (GA).

Design/methods Prospective, case-controlled study conducted in 16 sites (ARG, CHL, USA and BRA) during 18 months. DR management followed NRP guidelines. Eligible cases were NB $\geq 34 \mathrm{w}$ GA receiving AR at birth and the 4 consecutive NB not requiring AR were selected as controls for the study. Exclusion criteria: prenatal diagnosis of major congenital malformations. Univariate analysis and multivariate logistic regression (MLR) were used to estimate OR and the associated $95 \%$ CI.

Results From 61,593 deliveries, 58,429 NB were $\geq 34 \mathrm{w}$ GA $(95 \%)$. Out of 219 NB receiving AR (0.37\%), 23 were excluded, resulting in 196 cases and 784 controls. We found 21 RF

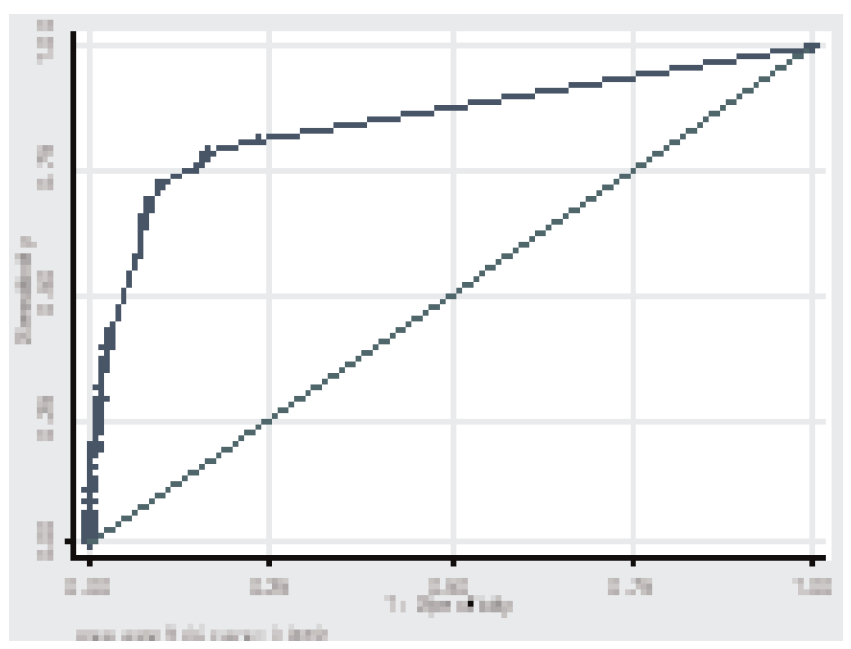

Abstract PS-225 Figure 1 


\section{Abstract PS-226 Table 1}

\begin{tabular}{|c|c|c|c|c|c|c|c|c|}
\hline & TP & & & & SIB & & & \\
\hline & 40 & 60 & 80 & & 40 & 60 & 80 & \\
\hline$V_{R^{+}}$ & $39.7(0.3)$ & $59.8(0.5)$ & $79.8(1)$ & p Value & $39.8(0.2)$ & $59.8(0.4)$ & $79.6(0.7)$ & p Value \\
\hline Inspiratory tidal volume ${ }^{\dagger}$ & $27.9(16.6)$ & $22.6(7.4)$ & 19.3(4.1) & $<0.001^{* *}$ & $33.4(17.7)$ & $25.8(9.7)$ & $24.4(5.1)$ & $<0.001^{* *}$ \\
\hline Mean Airway Pressure ${ }^{\dagger}$ (MAP) & $8.9(2.1)$ & $11(1.5)$ & $11.5(1.6)$ & $<0.001^{*}$ & $5(2)$ & $6.5(1.8)$ & $8.2(1.7)$ & $<0.001^{*}$ \\
\hline I/E Ratio ${ }^{\dagger}$ & $0.26(0.25)$ & $0.43(0.8)$ & $0.48(0.18)$ & $<0.001^{*}$ & $0.35(0.25)$ & $0.45(0.2)$ & $0.67(0.23)$ & $<0.001 *$ \\
\hline
\end{tabular}

† Mean (SD) * RM ANOVA ** RM ANOVA on ranks

statistically associated with AR. The MLR correctly classified $87 \%$ of the observations.

Conclusion $\mathrm{NB}$ of pregnant women presenting the following RF: GA < 37, EC, MFL, CC, FB, AP, MSAF, ECS, Ga and PROM (Premature rupture of membranes) $>18 \mathrm{~h}$ have an increased need of Advanced Resuscitation (AR). Team trained to should be present at the delivery for pregnant women with the above risk factors.

MLR to AR

\section{PS-226 EFFECTS OF DIFFERENT VENTILATION RATE (VR) TARGETS IN A MODEL OF NEONATAL MANUAL POSITIVE PRESSURE VENTILATION (PPV)}

C Cocucci, L Acha, G Musante. Neonatology, Hospital Universitario Austral, Pilar - Derqui, Argentina

\subsection{6/archdischild-2014-307384.525}

Background Current recommendations for manual PPV in the delivery room allow a VR range of $40-60$ ventilations $/ \mathrm{min}$. However, not enough studies have explored the effects of VR on resuscitation.

Objective To evaluate the effect of different VR targets on other ventilatory variables during manual PPV.

Methods 20 physicians manually ventilated an intubated neonatal manikin with both a self-inflating bag (SIB) without a PEEP valve and a T-piece resuscitator (TP). Peak inspiratory pressure

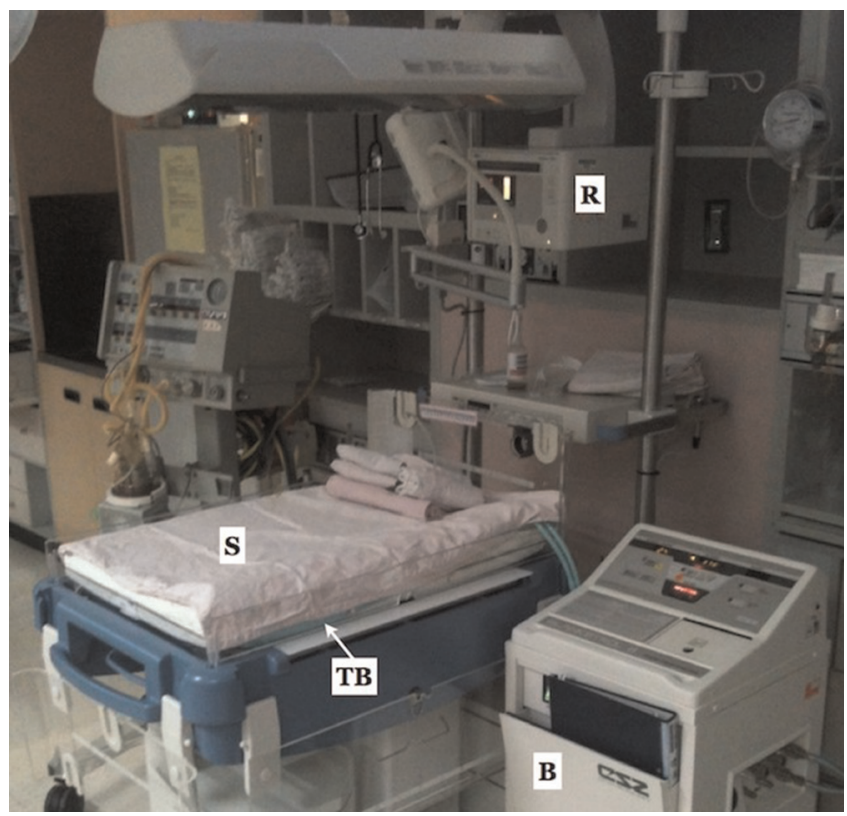

Abstract PS-227 Figure 1
(PIP) target was $25 \mathrm{cmH}_{2} \mathrm{O}$, PEEP was set to 5 on the TP and flow was kept at $8 \mathrm{l} / \mathrm{min}$. VR (40, 60 and $80 \mathrm{vent} / \mathrm{min})$ was paced by a metronome. Both, VR targets and PPV device sequences, were randomly assigned. Variables were compared by one-way repeated measures ANOVA.

Results Participants performed 9450 ventilations in 6 series of 90 seconds. For both devices there were no significant modifications in PIP and inspiratory time $\left(\mathrm{T}_{\mathrm{i}}\right)$ between VR targets.

Conclusions Higher VR increased I/E ratio and provided higher MAP despite similar PIP. Further studies are needed to evaluate if targeting VR can influence the response to PPV in delivery room.

\section{PS-227 A RANDOMISED TRIAL OF USING THERMAL BLANKET TO IMPROVE THERMOREGULATION AMONG PRETERM INFANTS}

KH Hsu, MC Chiang. Division of Neonatology Department of Pediatrics, Chang Gung Memorial Hospital and School of Medicine Chang Gung University, Taoyuan, Taiwan

\subsection{6/archdischild-2014-307384.526}

Background Thermal protection is critical in caring very low birthweight (VLBW).

Methods VLBW infants born at Chang-Gung Memorial Hospital were randomly assigned to $\mathrm{TB}$ or control group from February to July 2013. All infants were placed on a pre-warmed radiant warmer upon admission. For TB group, blanket of Blanketrol ${ }^{\circledR}$ II (Cincinnati Sub-Zero Products) was additionally applied (Figure 1) and system temperature was set $37^{\circ} \mathrm{C}$. Individual's temperature, heart rate, mean blood pressure (MAP), and oxygen saturation were measured immediately at admission and at 30th, 60th, 90th, 120th minute later, respectively. We defined hypothermia as temperature $<36^{\circ} \mathrm{C}$ and hypotension as MAP $<$ index infant's gestational age (GA).

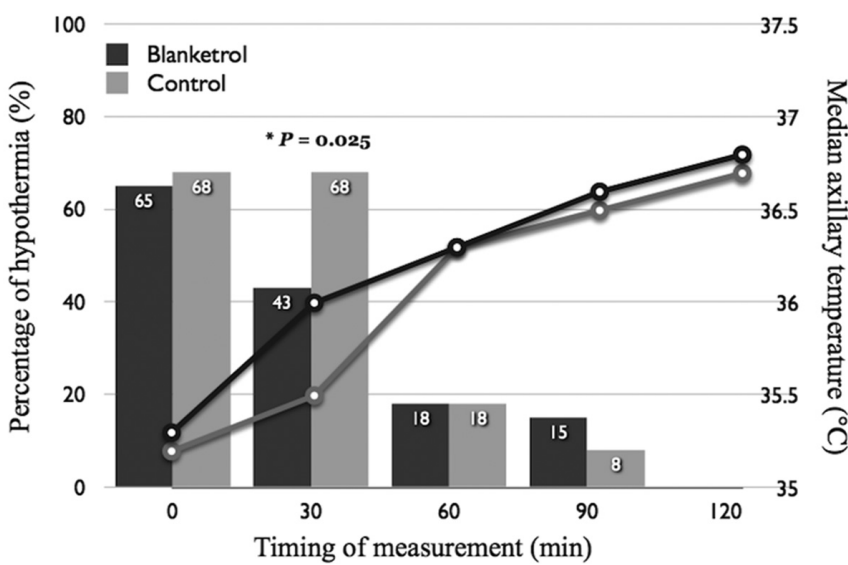

Abstract PS-227 Figure 2 